\title{
Dark Matter in the Organism
}

\author{
Martin Vlček* \\ eFunctionality-non e profit research group, Czech Republic
}

Submission: November 15, 2017; Published: December 4, 2017

*Corresponding author: Martin Vlček, eFunctionality-non e profit research group, Czech Republic, Tel: +420 737 164 850;

Email: martin.vlcek@efunctionality.eu

\section{Dark Matter}

\section{Introduction}

Dark matter is a euphemistic notation stemming upon an analogy with the interstellar dark matter and from its estimated role in functioning of the universe. In a certain exaggeration it is only an estimation of the author what is of course not generally accepted. There is even not a known concrete person accepting it. But it is not possible to exclude it=. This dark matter-later on only DM-is a part of control evaluating dynamic of existence of the controlled (holistic) object and in a control of non-dark, normal, visible matter (NM) It proceeds on basis of its experience.

Principe of holistic control in what at the top of controlling pyramid is the dark matter DM is realized in the organism throughout a certain "water structure". It goes about a part of control what is not submitted to an immediate productive or biochemical influence of the organism connected with flow of energy. It is not a part of its productive structure. It stays outside of it and its role is to activate top levels of the central nervous system on basis of evaluation of its functioning. Later on as an example of a living organism the human organism will be discussed in a degree in what its physiology is known to the author. DM is situated into the cerebrospinal liquor (CTF) and into a part of lymphatic system.

\section{Principle of control}

In holistic systems DM is charged by evaluation of information about satisfaction of elements and of the whole object. It is a part of control evaluating the existence of the object itself and on the basis of this activates other parts of control-more concretely the consciousness. Existence of any object is followed on its tendency to leave the structure in what it is at a given time engaged. As high is this tendency as high is the measure of its dissatisfaction and as low is its measure of existence. Because cells in the organism cannot as elements leave the object this tendency is followed up one level lower. Then it goes about a satisfaction of water as an element of a cell and that is why about its tendency to leave cells.

Besides of this a satisfaction of the object as whole is monitored. The structure in what it is engaged is a structure in majority formed by other organisms (humans) in its environment. And so called emotional relations are decisive here. They define decisive distances in this structure and that is why they are used for evaluation of satisfaction of the organism as whole-of a human. DM is a structure formed by molecules of water able to evaluate information about satisfaction of cells. It goes about a structure staying upon hydronium relations (self-ionization of water) similarly as it is in cytoplasm of cells. It goes about a very unfamiliar area but its involvement as DM is necessary. It stays perhaps upon information coming from lymphatic vessels and its output is mainly in the area of cerebral cortex. And for new through hydrogen and hydronic bridges, respectively of their dynamic.

Very important as a part of control of the satisfaction of cells is in this context also the immune activity in lymphatic system. In what about the satisfaction of the whole organism it is perhaps evaluated in the limbic system and during the work of cerebral cortex there is an interconnection of these two influences: the aggregated satisfaction of cells through CTF and the aggregated satisfaction of the organism from the limbic system. But it is also possible that the satisfaction of the organism firstly pass through CTF. It would better correspond to found out principles in analogical holistic systems.

\section{Event of satisfaction}

As a result of aggregation of information about distribution of satisfaction of cells into CTF there is an activity reaching the output from DM as an event starting up the activity of cortex. More exactly it goes about a switch of the consciousness. Every individual event defines a step of individual time of organism. And just at this time the consciousness in cerebral cortex is activated. At the same time this activity is a manifestation of a fact that there is a reason for an activity. Pass the existence is in danger fail it is possible to improve it. In both cases it goes about a situation meaning in its consequence a possibility of an augmenting of level of existence in comparison with an alternative of non-activity. The cerebral activity invokes another activity in $\mathrm{NM}$ what in its final consequence will remove or tends to remove the non-satisfaction. This is the basic feedback and a basic loop 
of control of the organism. The event of satisfaction of cells has probably to its disposal some quick feedback. It goes about involvement of the immune system in an immediate reaction to some local non-satisfactions. Thanks to this information for new coming perhaps through lymphatic vessels there is an activation of mechanisms of defense.

\section{Emotional relations}

Emotional relations are relations having all the time a same orientation of their influences on the existence of the organism. All the time the influencing output is despite of some variability of its value only positive or only negative. It goes mainly about relations between organisms of same kind, e.g. about human relations. Seat of this evaluating part of control is seemingly in the limbic system. If an emotional relation is to be long-time "emotive", what means that its influence on a given organism is to be preserving all the time its orientation, it is necessary to be a mutual relation. What means to be positively emotional for both organisms? For every given emotional relation there is defined by a standard manner a distance in holistic system. It is given by volatility of its values. As smaller is the volatility as lower is the distance. And this is its typical property to try to change this distance in a manner to minimize or optimize it in a case of positive emotional relation and vice versa. But this is already a standard sequel of a standard principle of control. Organism characterizes itself by the fact that at the moment of its nascence it inherits them. That already from the beginning it is determined what is for its existence a favorable relation. The organism, more exactly its existential substance, is thus from the beginning determined.

\section{Normal Matter}

\section{Introduction}

So as DM works with satisfaction, the NM works with successfulness. Successfulness is level of participation into a system and NM follows singularities in its distribution. They are a way toward any activity and finally toward a solution of the main task-improvement of the existence.

\section{VED}

VED-differently speaking consciousness of the organism-is a spot what already doesn't work with the satisfaction. Nor of cells and nor of the organism. It already doesn't go about a part of DM but about a top part of control of the NM. Similarly as in DM an aggregation of information about distribution of satisfaction into one event connected with a known solution happened; also here an analogical situation happens, but of course in distribution of the successfulness. VED forms a global event from information coming from different areas of NM, mainly from the area of material inputs, inputs of energy and about a tension on the border (results of economical calculations).It goes about an activity being the substance of the consciousness and on its basis an output from VED happens. That is why it happens only in the end of a process of identification when a solution is found. And just this solution is the output activating reconstruction of the organism. Majority of an output goes into a reconstruction of the border - into a movement. As result of this fading of initial event of satisfaction identified in DM and starting the whole process of control happens.

More concretely the control activity from DM is transferred into VED through way of CTF and through appropriate areas of cerebral cortex. It is an activity typical to the DM, what means a dynamic of "hydronic", water and hydrogen structures. This one is seemingly also used for identification of a global event in this area that is why for constitution of the consciousness. It goes about the fact to make the aggregation of information inside the cortex a really global one. To make America strong again=!

\section{Tension}

A tension arises when there is a non-even distribution of activities where evenness is expected. E.g. in a group of similarly specialized cells it can to be expected that their activity will be to some extent synchronous. The tension is evaluated flowingly. In a group of similarly specialized cells a distance of the specialization is defined. That is why if two cells are identically specialized and their difference is only in place of their engagement, in their magnitude etc., their distance is null. And inversely. Let difference in their activity is evaluated then. The tension between them is just this difference divided by the distance. As high is the difference of activities and as low is their distance, as high is the tension. Then the total tension in a group is the highest value among these values inside the group.

\section{Solution of a tension}

Philosophy of activity of VED is seemingly built upon following scheme. Let is taken into account that an event in satisfaction is solved. But it is not known of what form and on what places its singularities are. That is why it is necessary to start from a fact how different level of satisfaction reflects itself on successfulness. And here a fundamental preposition is made: a less satisfied element is frequently at the same time less successful. It doesn't need to hold every time but in great numbers it does. That is why if VED will follow singularities in successfulness there is a supposition that it will as a sequel follow and solve singularities in satisfaction.

As it was already mentioned VED solves this tension on inputs mainly through the activity on the border, what means a movement of the organism. Generally speaking it goes about any reconstructions of structures what will be reflected into the starting up event of satisfaction.

And similarly as in the case of DM,the finding out of a global information in VED signals that a solution is found, too. And this is a global activity on outputs from VED, what in the past proved itself to be successful in solution of a found event of tension of successfulness. And similarly as in the case of DM also this aggregation is a result of usage of stimulating and inhibiting instruments. 
Not only information about material inputs but also about distribution of inputting energy, about tension on the border and about tension in distribution of successfulness can reach the consciousness. At least calculations on economic structures show it. For new these are information only completing the initial informatics input from material inputs. Tension into energy is primarily not differencing from tension in material inputs. It only shows on a place where similar elements non equally intensively work. That is why it is only a quantitative enlargement.

A tension on the border signals a certain disproportion in its disposal. It is logical that in a case of similar activities also the border should be similar, of a similar shape. VED uses for solution of global existence just these borders and a safety fuse has to be here. Some combination of movements can on one side solve the existential threat but on other one represents a too high, unsustainable tension on it. And what is unsustainable is recorded just in experience of cells in VED. If sometime in the past a similar deformation of the border led to problems, e.g. existential, then it is their task to discover it as an impeding tension what needs to be solved. And this means to enter into the consciousness.

\section{Satisfaction vs Successfulness}

In general it is desirable to make all cells having a satisfaction as similar as possible. In other words everybody how belongs to the organism should to feel itself similarly. From this reason DM during its evaluation of an event doesn't take into account position of the cell into productive structure. There is an aggregation but not on a basis of the type of position but on a basis of a placement into the organism. E.g. all cells from one organ or from one its part ought to be similarly satisfied and the same holds for another one. And the aggregation is then possible over organs and in a comparison of an average value of satisfaction. From calculations follows that the aggregation happens also on basis of distribution of energy. That is why nothing connected with the productive process is differentiated, only common properties, common for parts of the organism producing e.g. quite different metabolites. E.g. less energetically demanding part forms one potential group etc. In general task of the DM is not to remove low non-satisfactions. Its task is to remove the tension (!) in satisfaction. It means that a too high satisfaction optically too "sticking out from the cloud" is undesirable, because it forms a tension. More likely it is possible to say that the task of DM is an even satisfaction on an as high as possible level.

In contrast with this an aggregation of successfulness and of its singularities in NM is built upon the fact how active are elements in the structure. It can goes about e.g. a situation when a cell is quite indispensable but is constantly overloaded and tending towards a collapse or another not so dramatically fall. That is why it can be extraordinarily successful but at the same time extraordinarily non-satisfied.

In contrast with satisfaction and DM the task of VED is not to reach an even successfulness. Without tension in successfulness it would not be possible to find out a solution of an event of satisfaction. And in contrast with this an event of satisfaction needs not to happen at all and evenly it represents in a certain way an ideal state.

\section{Repression}

Organism has to have a possibility to relieve itself from elements what are from point of view of DM inconvenient. Differently speaking DM tries not only to smooth the satisfaction and to improve it, but in a case of necessity to ensure a departure of non-satisfied elements. Because these ones form a certain potential threat for the future. That is why, on a basis of information about satisfaction of an element and about e.g. average satisfaction in adequate area of the organism, the element will be killed. Its position will be free and there will be a supposition that a new "applicant" will be normally satisfied. This function is seemingly realized by the immune system.

\section{Your next submission with Juniper Publishers} will reach you the below assets

- Quality Editorial service

- Swift Peer Review

- Reprints availability

- E-prints Service

- Manuscript Podcast for convenient understanding

- Global attainment for your research

- Manuscript accessibility in different formats

( Pdf, E-pub, Full Text, Audio)

- Unceasing customer service

Track the below URL for one-step submission https://juniperpublishers.com/online-submission.php 